\title{
Understanding the Critical Role of Applied Linguistics with Other Disciplines of $21^{\text {st }}$ Century
}

\author{
Ali Siddiqui \\ English Language Development Center (ELDC), Mehran University of Engineering and Technology (MUET), \\ Jamshoro, Sindh, Pakistan \\ Shabana Sartaj \\ Department of English, Sindh Agriculture University, Tandojam, Sindh, Pakistan \\ Abdul Karim Keerio \\ English Language Development Center (ELDC), Mehran University of Engineering and Technology (MUET), \\ Jamshoro, Sindh, Pakistan
}

\begin{abstract}
The present study describes the need and importance of Applied Linguistics in present world. It aims to explore all the areas of applied linguists, where it plays a major role. The introductory section describes applied linguistics with its definitions along and references to renowned authors. The second part discovers a brief historical view of applied linguistics that represents it as a distinct field to explore. It portrays about the emergence of this field that is changing with different periods by its professional and academic activities. The third part of a study demonstrates the scope of applied linguistics and its relation to other disciplines. It suggests the future development of applied linguistics with the emerging new scientific disciplines. The fourth section highlights a hot debate of a current scenario that shows the vitality of applied linguists with respect to Linguistic Human Rights (LHRs). The paper aims to explain the importance of applied linguistics around with current perspective of World. Later, it reveals the real situation to violation of Linguistic Human Rights (LHRs) that are specifically contextualized within states of Pakistan and India. Along with this, it also portrays the picture of the future World to a case if no sincere efforts are taken to protect the Linguistic Human Rights, it can prove fatal for researchers and teachers of applied linguistics in general. The final section concludes a study with an over view of applied linguistics to its historical perspective and its relation with other disciplines, specifically with Linguistic Human Rights.
\end{abstract}

Index Terms — applied linguistics, language problems, scope, Linguistic Human Rights (LHRs).

\section{INTRODUCTION}

Language works at the heart of human existence. In this modern world, where every other individual is surrounded with new technological inventions and progressive education marks but at the very same time, they still left with many questions that are related to educational and social problems within the civilized society. To answer these questions, it is reasonable to explore and understand the use of language constructively. With the help of investigation, the gained knowledge is structured and formulized into rational deliberation and critical analysis. This whole process leads to the action that is taken as part of practice for the present problems. This is what Applied Linguistics is meant for. Linguistics is taken as the scientific approach to study a language. Therefore, Applied Linguistics is concerned with language-relevant research that is applied to solve the language problems which has a significant validity within the real world. According to Kaplan and Widdowson (1992) opinion; "Applied Linguistics is practiced where every language problems are dealt, like of how languages can be taught in a better way, how the examinations should be conducted in order to test one's language learning and how language planning policies should be made to save and develop many other indigenized languages by their proper implementation as well. The word 'Applied' itself is considered as a kind of technology that develops ideas and research findings to solve language issues within a given society. Therefore, the field of applied Linguistics intervenes between theory as well as its practice. According to Grabe (2002), the field of applied linguistics is mainly focused to give a try in resolving different lingual issues for which people usually face in relation to their real world situations. No doubt, the positions do very at every phase, they may they be the language learners, tutors, who teaches a language, a supervisor to language activities and academicians, the professional outlook may either be concerned with professions of law, along with the services that provides, what is required to deal in many other social services. The example of test takers can also tend to measure the requirements, so are the policy makers, lexicographers, the translators, who translates the business transaction and it is so sum of entire range that acknowledges business clients. According to Corder (1974), who has rightly pointed about the field of applied Linguistics as it is the application of knowledge which is gained from linguistic research in order to improve the effectiveness of some realistic tasks to language is taken as a main component of study and practice. It is therefore 
stated that the field of Applied Linguistics uses and draw theories from other relevant fields that are either directly or indirectly concerned with a language use. It creates its own theory with the aim of finding solutions to the languagebased issues in the social world.

\section{HISTORICAL OVERVIEW OF APPLIED LINGUISTICS}

The field of Applied Linguistics as a separate discipline was introduced in 1948 when first journal was named "Language Learning: A journal of Applied Linguistics" published in this respect. In 1950s, Applied Linguistics was meant to explore Second Language Teaching (SLT), language arts and first language literacy issues. Later in 1960s, this was meant to be applied within language teaching domain, which had direct relation with the practical issues. According to Davies (1999); the mid of end 1960s have witnessed that the field of Applied Linguistics emerged as an authentic language-centered problem solving activity. In 1970s, this field emerged at a broader concept that focused not only on language-based issues of the real world but it also took insights from many other grown natural and social sciences sub-fields, like language policy planning and its implementation, the issue of bilingualism and multilingualism, Second Language Acquisition (SLA), language assessment, language minority rights to name the few with still many other practical disciplines. In 1980s, the field of Applied Linguistics extended systematically by moving from one step beyond disciplines of language teaching and learning issues. It has also engaged itself with unsolved provisions on language use within professional situations. Till 1990s, the Linguistics and Applied Linguistics both fields were considered as separate and diverse fields of research agendas. According to the British Association for Applied Linguistics $(B A A L)$, it was defined as "it is study of language use, learning, teaching and development of interdisciplinary association". Whereas on the other hand, according to the view of Davies and Elder (2004), they claimed that it was decision by British researchers to describe about Applied Linguistics as an independent field of study. Therefore, other models should be constructed by Applied Linguists in research domains by carrying the path of research to various other subtle issues. According to Corder (1973), the concept given was that an observation within the field of linguistics is intimately connected with applied linguistics when it comes to explain the language. Later, Widdowson, (1984), raised an argument. According to the argument about the issue of language that has explained the linguistic models by showing an analyst's point of view on language with a criterion under applied linguistic models that shows language users' perceptions to language related with their real world situations, which are commonly neglected in practices of teaching and research. After twenty century, the concepts seemed to emerge more in these respective fields. Davies and Elder (2004), have rightly point out the distinction between linguistics and applied linguistics. According to Davies and Elder (2004), the field of linguistics is concerned primarily with a language as an end itself along with diverse language issues which are the main sources to present evidences towards acknowledging of language description in a better way. It can be even further linked with explanation of a linguistic theory. On the other hand, the field of applied linguistics is moreover focused on language with its problems that could reveal a significant role within pupils' personal and collective daily lives to as desire for whether its intervention could be possible or is it a mere wish.

\section{SCOPE OF APPLIED LINGUISTICS IN PRESENT WORLD}

\section{A. Importance in Field of Research}

Applied linguistics mainly focuses on the research in learning, teaching and education that further reinforces the concepts of learning with proper attention, language awareness, and the ways of student-teacher interaction, the taskbased teaching and action research that are carried by teacher as a the researcher. The focus has been shifted towards development of language of teacher as well. The teachers can engage themselves within the process of action research. Teaching and learning processes show effective progress in local classrooms because teachers are trained as reflective practitioners.

\section{B. Importance in Critical Studies}

The words 'critical study' are itself the umbrella terms that connotes with many other related notions like Critical Discourse Analysis (CDA), critical assessment practices, critical pedagogy and ethics in language assessment. According to William Grabe (2010), the application of aforementioned critical studies which are still under process, where one finds many other language issues but still the support to this debate may be continued.

\section{Importance to Language Use}

Applied Linguistics has explored much other varied form of ways which participants do usually use language in their professional and academic settings. It also explores many other forms through which use of applied language can be claim by knowing that the ways language can work as a mechanism to create problems if one is not aware of using appropriate conversation by regulations and expectations.

\section{Importance to Corpus Linguistics}

The Application of corpus linguistics can be supported by occurrences of language use within provided large quantity of knowing the Basic English terminologies. The solution behind is hidden in the original analysis and demonstrations 
rather than corpus data itself which further have described the exclusivity of grammar. Teacher- centered and learnercentered resources are also one of the important applications of corpus linguistics.

\section{E. Importance to Bilingualism and Multilingualism}

Since a large portion of the world is bilingual and multilingual. It is therefore the field of applied linguistics usually does focuses on two important notions of bilingualism and multilingualism which tend to contact through community, school and professional settings. It does explore the policy issues at national and regional levels. The issue of bilingualism is related with necessity for discussing the real life situations with other language and cultural groups. Whereas, the notion of multilingualism does focuses on the problems that usually occurs in bilingual education, migrations done by the people to new language settings, fairness and formation of equity in social services along with language policies that are concerned with use of multiple languages.

\section{F. Importance to Changing Methods of Language Testing and Assessment}

In the recent past centuries, the notion of language assessment has remained as one of the hot debates which stand at the center of knowledge measurement. The aspect of Validity has remained as a major issue for the language testers and takers. It is the job of applied linguists to give new insights for the new interpretations which are regarding to this serious matter. According to Chapelle (1999), the research aspect of validity has strong implications for all areas of applied linguistics research and specifically to procedure of data collection. Therefore, it is not simply an issue for assessment practices only. It is because of the applied linguists that a great emphasis has been shifted towards the assessment of language learning. The way of assessing students at a given particular interval of time has been shifted to assessing students in a way that can improve their learning effectiveness on ongoing basis. The goal of learner's assessment is to evaluate in all of whether the continuous learning purpose is helpful to achieve the required target or still it needs some more? In this respect, the field of applied linguistics emphasis on technological applications, ethics in assessment, innovative research methodologies, the roles of standardized assessment, standards for professionalism and critical language testing that are all reshaping the language assessment process.

\section{G. Importance to Neuro-linguistics}

The famous but rarely researched field of Neurolinguistics is one of the major branches of linguistics which demands more to contribute. It is likely to be related with language usage and its proper learning. Though, yet the scholars fail to fully prove its direct contribution with the concern to field of applied linguists. However, the medically, the formation of signs for usage within brain and language learning are recorded that can be reflected towards relation within itself. Therefore, this relation between the ways mind functions to that of language learnt is great phenomenon. It is therefore, researched and further suggested $b$ linguist scholars that this field in future may probably become a significant sub-area of applied linguistics which a century can mark its literal progress in technological advanced decade.

\section{APPLIED Linguistics AND LingUistic HumAn RigHTS (LHRS)}

After having proved the relation of applied linguistics with other social and natural sciences, it is significant to explain the way it is linked with advanced linguistics human rights (LHRs). It is rather a specific topic and is related to field of linguistics which mainly concerns about Linguistic human rights that remained as one of the hot debate within our local context. It is because the phenomenon of Language is that factor of human's life which shapes the overall ethnic identity of individual and collective phases. When, one is referring that all of the individuals should have the benefit for a universal linguistic human right then, there is a job of applied linguists that they need to explain all the political realities of subtle unequal power relations that resides with a multi-lingual platform. According to Robert Phillipson (1992) and Tove Skutnabb Kangas (1995), they have rightly pointed out some myths of degenerative concept regarding language death. The myths are still studied and famous to take as one of the sociolinguistic research forum.

a. The first and most important myth that is still available was the rising percentage of people who uses one

language. They are termed as monolinguists and this phenomenon is known to be as mono-lingualism. This phenomenon has many aspects of monolinguist hold and advantages that focuses on to economic development of one community on behalf of other's expenses. Besides this, the phenomenon of mono-lingualism has openly violated the Linguistic Human Rights (LHRs) within a multilingual state forum.

b. The second myth is about the minority community. The rights of many minorities are threat to worst in a state. Since the Applied linguists does play a significant part to introduce this chapter in constitution, legitimation and reproduction of language hierarchies that tend to survive nationally as well as internationally. Therefore, this is the great challenge for applied linguists and common man to elucidate those policies, which tend to implement with either to meet the worldwide standards or for Linguistic Human Rights which on apparent vision not possible.

c. The third myth, which is less important than above two, but still is considered as important to discuss with reference to those languages which are used in some of the powerful domains like education, politics, law and etc. These some of them are usually known in sociolinguistics as dominant languages. They in common terms are also named as official, international or even national languages. Therefore, such types of acknowledgements that reveal something about extra linguistic purposes have served languages themselves to face various questions, for which its 
speakers fail to answer. It is duty of applied linguists to answer for which they are mainly concerned with whether their activities does validate to standards of basic human rights (HRs).

The reference of International law states that the minority communities of linguistic concerns are openly allowed to use their languages as free individuals within their communities. The question arises then, where does problem of language subservience then exists at the national level?

The common answer that can satisfy the need of this question asked can be as the state itself is involved to suppress much of the identities of minor ethnic communities by its failing to provide an adequate power to minor languages, which are still dying in many cases within Pakistan. Moreover, the state is allowed to endorse multi -languages as national languages that cannot even discriminate minor languages at many of the occasions. However, it rather an unfortunate situation, where for the few political and an economic reason itself, the minor languages are mainly discriminated on regular basis. If it continues then state will have to lose different flowers as languages that symbolizes to make a garden as a world when are combined. According to David Crystal (2005), an Internationally recognized research linguist, have maintained that around 6000 languages that still exists today will soon disappear in coming years if serious and constructive efforts are not made in this respect to save them on possible time before it becomes too late. They are so closely connected with individual's fundamental rights like rights of culture, rights of education and to greater extend up to rights of expression. It shows that the case of India is almost the same of Pakistan. According to one survey of 1991 on languages, it was stated that around eighteen Indian languages which includes Punjabi, Tamil and Urdu with their 85 mother languages are spoken by less than almost four percent of the population. A great number of these languages have less than 10,000 speakers only. They are almost of age old resided tribal people which speak those mother languages that are almost at verge of extinction.

Similarly, the dominant languages of the world are swallowing the minor ones slowly and gradually with linguists and layman stands aghast. If the sincere steps are not taken now, then many other minor languages may disappear from this world. Now-a-days, the phenomenon of globalization along with the recent advancement of information technology has started to maintain the marketing of languages which are also used as commodities. Therefore, as a result of linguistic diversity that is at high risk of extinction, standard languages are given a high importance by a great number of consumers who does have the capacity of spending the funds for its regulation internationally. Whereas, the problem lies with languages of minority groups, specifically to those which are spoken with reference to tribal people, living in far distant areas and they even lack basic facilities for the proper propagation of their dialect. It is an extremely sorry state for a state that claims to be a multilingual state, Pakistan. The issue is signaled as deprived linguistic human right. It is therefore, the people in order to survive successfully have adopted the learning of foreign language and they tend to prefer that language with masters and usually shift towards that language. The above briefly discussed phenomenon have made it compulsory to understand the entire language scenario with proper notion to bring positive and innovative policies within assemblies of language policies for giving linguistic rights to the tribal people. However, the language policy can be reviewed by keeping in mind the provisions of Universal Declaration to Linguistic Rights (UDLRs). It is mandatory to respect the linguistic rights of indigenous people so that their mother languages can be protected and valuable knowledge related to their indigenous areas can also stay safe for future centuries.

\section{CONCLUSION}

It can therefore be stated that field of Applied linguistics is itself an interdisciplinary field when it comes under the two separate domains of research and its practical paradigm. The practical paradigm is directly concerned with more often to realistic problems which are faced by people towards the language, when they study as well as made it in communication. The realistic problems are tending to be identified and then analyzed with its final step to solve through varied applying theories, approaches and its sub-approaches. It also develops new methodological and theoretical frameworks that work to solve and explore the real life problems. Applied linguistics refers to a broad range of activities that involves solving of language-related problems or addressing some language-related issues. It was first officially recognized as an independent course at the University of Michigan in 1946. In those early days, the term was used both in the United States and in Great Britain. It then became a 'scientific approach' to teach foreign languages that included English for non-native speakers. This field started to develop after 1990s. Today, the field of applied linguistics is described as the means of helping to solve varied specific problems within society which core linguistics failed to get the real answer. Applied linguists have therefore, focused on the numerous and complex areas within society in which language itself plays a vital role. The goal is to apply the findings and techniques from varied research topics within linguistics and other related disciplines in order to solve practical queries. To an observer, the most prominent change in field of applied linguistics has been its rapid growth as an interdisciplinary field. In addition to this, foreign language teaching and machine translation are the major disciplines that are considered as central to the field of applied linguistics today. It includes many topics such as Language for special purposes (LSP), language and communication problems, language disorders, law, medicine science, Language policy making and literacy issues and etc. Some of the applied linguists are only concerned with helping planners and legislators in countries to develop and implement common man benefit language policies. These for example can be in shape of planners that are working in India and Pakistan to specify and further develop roles within education as well as government for not only to English language but also for the indigenous languages. It helps the specific groups to develop scripts, materials and literacy 
programs for previously unwritten languages. Other topics that applied linguists work are the broad issues of the best possible role to represent a native language within education of culturally and linguistically diverse students, the language of influence and politics towards level of language testing and evaluation. It highlights the main issue of present world's scenario regarding Linguistic Human Rights (LHRs). The imposition of a standard variety on the indigenous varieties to ghettoized people marks a violation of their linguistic human rights. It highlights Language policies of the countries that are supported with respect to power relations. The mother language of powerful native groups has become the dominant languages politically as well as economically. These are the main issues that still needs more exploration with current time can be made to solve by applied linguists.

\section{REFERENCES}

[1] Chapelle, C. A. (1999). Validity in language assessment. In W. Grabe et al. (Eds.), Annual Review of Applied Linguistics: Vol. 19. Survey of Applied Linguistics (pp. 154-272). New York: Cambridge University Press.

[2] Corder, P (1973). An Introduction to Applied Linguistics. Middlesex: Penguin Books

[3] Corder, S.P. (1974). Error Analysis. In J. P. B. Allen and S. P. Corder (eds.) Techniques in Applied Linguistics (The Edinburgh Course in Applied Linguistics: 3). London: Oxford University Press (Language and Language Learning).

[4] Crystal, David (2005). Pronouncing Shakespeare: The Globe Experiment. Cambridge University Press.

[5] Davies, A. (1999). An Introduction to Applied Linguistics: From Practice to Theory. Edinburgh: Edinburgh University Press.

[6] Davies, A., and C. Elder. (2004). General introduction: Applied linguistics: Subject to discipline? In A. Davies, and C. Elder (Eds.), The Handbook of Applied Linguistics (pp. 1-15). Malden, MA: Blackwell.

[7] Grabe, W. (2002). Applied linguistics: An emerging discipline for the twenty-first century. In R. B. Kaplan (Ed.), The Oxford Handbook of Applied Linguistics (pp. 3-12). New York: Oxford University Press.

[8] Grabe, W. (2010). Applied Linguistics: A Twenty-First-Century Discipline. The Oxford Handbook of Applied Linguistics.

[9] Kaplan,R.B. and H.G.Widdowson.1992. "Applied Linguistics". International Encyclopedia of Linguistics Volume 1.ED.W.Bright.New York: Oxford Univesrity Press.76-80.

[10] Phillipson, Robert. (1992). “Linguistic imperialism and linguicism,” Linguistic Imperialism. Oxford: OUP, pp. 50-57

[11] Skutnabb-kangas, Tove (Ed.) (1995). Multilingualism for all, Amsterdam: Swets \& Zeitlinger.

[12] Widdowson, H. G. (1984). Educational and pedagogic factors in syllabus design. In Brumfit, C. J. (ed.) General English syllabus design. Oxford: Pergamon. 23-28. [ELT Documents, 118.

[13] William Grabe. (2010). Applied Linguistics: A Twenty-First-Century Discipline. The Oxford Handbook of Applied Linguistics (2 ed.) Edited by Robert B. Kaplan DOI: 10.1093/oxfordhb/9780195384253.013.0002.

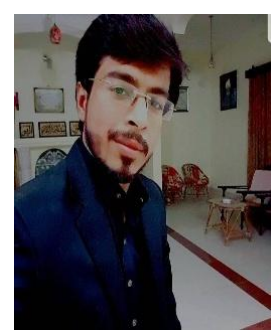

Ali Siddiqui (Author was born in Hyderabad, Sindh, Pakistan on 28-10-1993)

The Author is currently an M.S scholar of English Linguistics in ELDC, Mehran University of Engineering and Technology, Jamshoro, Sindh, Pakistan. He has done M.A (Masters of Arts) in English linguistics from University of Sindh, Jamshoro, Sindh, Pakistan with distinction (2016). The author is having research interest in English language teaching, research techniques in field of education and English for specific purposes. The Major Field of author's study is (English linguistics).

Mr. Siddiqui has secured ( $1^{\text {st }}$ position) in M.A English linguistics and is silver-medalist from University of Sindh, Jamshoro, Sindh, Pakistan.

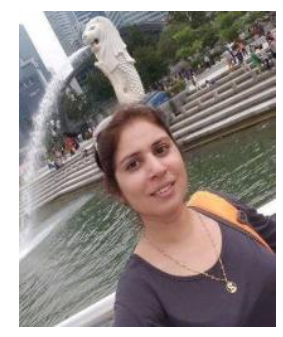

Shabana Sartaj (Co-Author was born in Shahdadkot, Sindh, Pakistan on 04 August)

The co Author is a PhD scholar in English Linguistics. The author has done PhD (Doctor of philosophy) from University of Science, Malaysia. The author did TEFL and TESOL from Allama Iqbal Open University (AIOU) in 2008 and masters in English literature from University of Sindh in 2005. The author is having research interest in Teaching English to large classes and English Language teaching (ELT). The Major Field of co-author's study is (English language Teaching ELT).

Currently, she is serving as the Assistant Professor at Sindh Agriculture University (SAU), Tando Jam, Sindh, Pakistan.

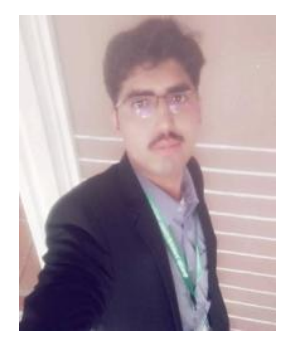

Abdul Karim Keerio (Co-Author was born in Badin, Sindh, Pakistan on 25-03-1996)

The co-Author is currently an M.S scholar of English Linguistics in ELDC, Mehran University of Engineering and Technology, Jamshoro, Sindh, Pakistan. He has done B.S (Bachelors of Studies) in English linguistics from University of Sindh, Jamshoro, Sindh, Pakistan in (2016). The co-author is having research interest in English language Applied research, Sociolinguistics and English syntax. The Major Field of author's study is (English linguistics). He is young active researcher in field of applied linguistics. 